\title{
Study of Concrete Aging Effect on the Contact Force and the Contact Time during the Impact of an Elastic Sphere upon a Viscoelastic Beam
}

\author{
Ivan Ivanovich Popov ${ }^{1,2^{*}}$, Ta-Peng Chang ${ }^{1, *}$, Yuri Alexeevich Rossikhin ${ }^{2}$ and Marina Vyacheslavovna Shitikova ${ }^{2}$ \\ ${ }^{1}$ National Taiwan University of Science and Technology, Taipei 10603, Taiwan, R.O.C \\ ${ }^{2}$ Research Center on Dynamics of Solids and Structures, Voronezh State University of Architecture and Civil Engineering, \\ Voronezh 394006, Russian Federation \\ *Corresponding Author
}

\begin{abstract}
In this paper the effect of concrete aging on contact force and contact time during the impact of steel ball upon a concrete beam has been investigated. Three concrete beams were tested at the ages of 7, 14, 28, 56, 91 and 182 days. It was found that contact force increases with concrete age, whereas the contact duration becomes shorter. The most significant changes occur at early ages, before 28 days, and this process slows down after this age: average maximum contact force is increased by $19.82 \%$ and average contact time is decreased by $20.87 \%$. This is related to concrete hardening: at very early ages concrete behaves more like a viscoelastic material and possesses a certain damping effect which is reduced with concrete aging.
\end{abstract}

\section{Keywords-viscoelastic beam; contact force; contact time}

\section{INTRODUCTION}

With worldwide growth of construction area, construction risks, obviously grow. Nowadays, many accidental impact actions on structural elements occur during its transportation, elevation, mounting, service and repair works. Some of them may cause the material microstructure changes in the contact zone and may affect its bearing properties, durability, stress-strained condition, stress distribution of entire structure etc., which, in turn creates additional risks. For safety reasons, those risks must be taken into account. A good way to estimate the damage of structures during the impact is to have a certain method to predict the behavior of the material under the impact loading. In this regard, it is important to estimate the contact time and contact force during the impact interaction.

In the previous work Rossikhin and Shitikova proposed two approaches for studying the impact response of a viscoelastic Bernoulli-Euler beam under the impact by steel sphere. The Young's Modulus of the viscoelastic beam was considered as a time-dependent operator and was defined either using the Kelvin-Voigt fractional derivative model or via the standard linear solid fractional derivative model. According to the first approach, Poisson's ratio is not an operator, but a constant. The second approach assumes that the bulk modulus is a constant. It was found that the solution obtained with the first approach is much simpler comparing to the one obtained with constant bulk modulus [1].
In this paper the way to estimate contact duration and contact force experimentally is proposed for the case when a viscoelastic Timoshenko beam is impacted by an elastic sphere.

\section{EXPERIMENT}

Within the framework of the experiment three concrete beams $(1000 \times 100 \times 100 \mathrm{~mm})$ and a batch of cylindrical samples (200 $\mathrm{mm}$ in height and $100 \mathrm{~mm}$ in diameter) have been cast (see Figure I). Mix proportions were designed according to ACI standard C211.1 [2] with the water to cement ratio of 0.41 (see Table I). Cylindrical specimens have been tested at the ages of 7, 14 and 28 days for the compressive strength, whereas the testing period for the beams was much longer: 7, 14, 28, 56, 91 and 182 days. All the specimens had water curing for a week, after that they were taken out of the water and cured in the air.

TABLE 1. MIX PROPORIONS ACCORDING TO ACI, KG/M ${ }^{3}$

\begin{tabular}{|c|c|c|c|c|}
\hline $\begin{array}{c}\text { Water, } \\
\mathbf{~ k g}\end{array}$ & $\begin{array}{c}\text { Cement, } \\
\mathbf{~ k g}\end{array}$ & $\begin{array}{c}\text { Fine } \\
\text { aggregates, } \\
\mathbf{~ k g}\end{array}$ & $\begin{array}{c}\text { Coarse } \\
\text { aggregates, } \\
\text { kg }\end{array}$ & $\begin{array}{c}\text { Superplasticizer, } \\
\text { kg }\end{array}$ \\
\hline 194.00 & 473.17 & 777.26 & 932.38 & 2.20 \\
\hline
\end{tabular}

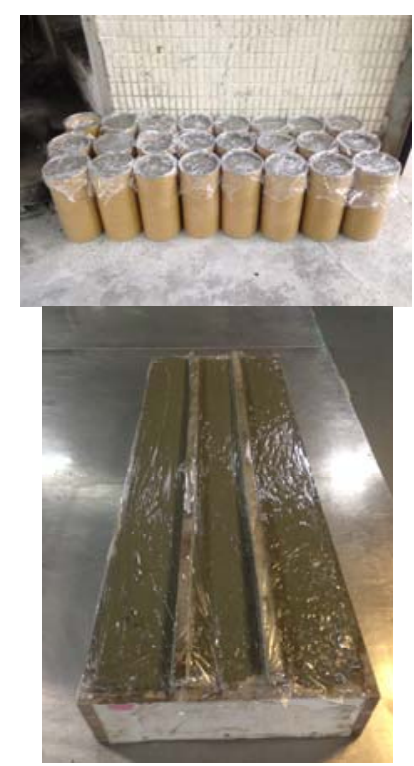

FIGURE I. CASTING OF CONCRETE SAMPLES 
In order to obtain contact time and contact force during the impact, the following experimental set up was constructed. A simply supported beam was impacted by a steel sphere, which in turn was dropped from the height of $100 \mathrm{~mm}$ in the middle of the beam. During the impact it is important to prevent the beam from vertical jump, otherwise the signal will be destroyed. For this reason, the ends of the beams were tightly bound to the supporting rod by steel wire. The mass of the ball is $261.19 \mathrm{~g}$. PCB 352C33 accelerometer is attached to the bottom surface of the beam, right under the impact point. Detected signal was transmitted to data acquisition system AD-Link and eventually was converted into digital signal. Visual Signal software has been used to transform and visualize the data. Impact test scheme and the experimental set up are shown on Figure II and Figure III, respectively.

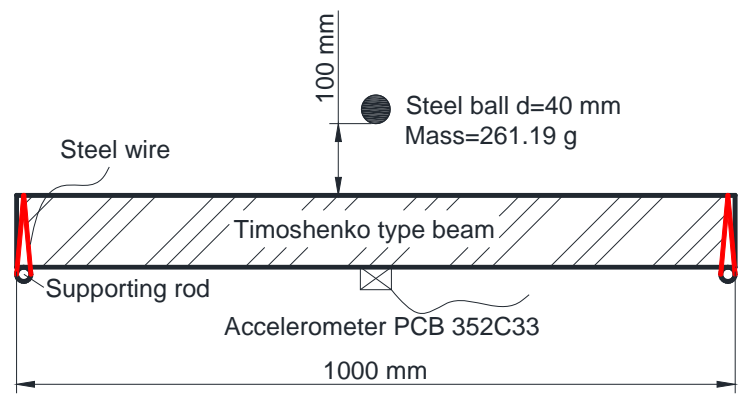

FIGURE II. IMPACT TEST SCHEME

When the data are obtained on PC and properly visualized, contact time can be measured as a half-period of the first vibration in similar way with the authors of the reference [3]. Scheme of contact time measurement is shown on Figure IV. Since the acceleration is recorded during the experiment, the contact force can be calculated by using the Newton's Second law. Contact force during the impact is a function of time and can be represented graphically as it is shown on Figure V.

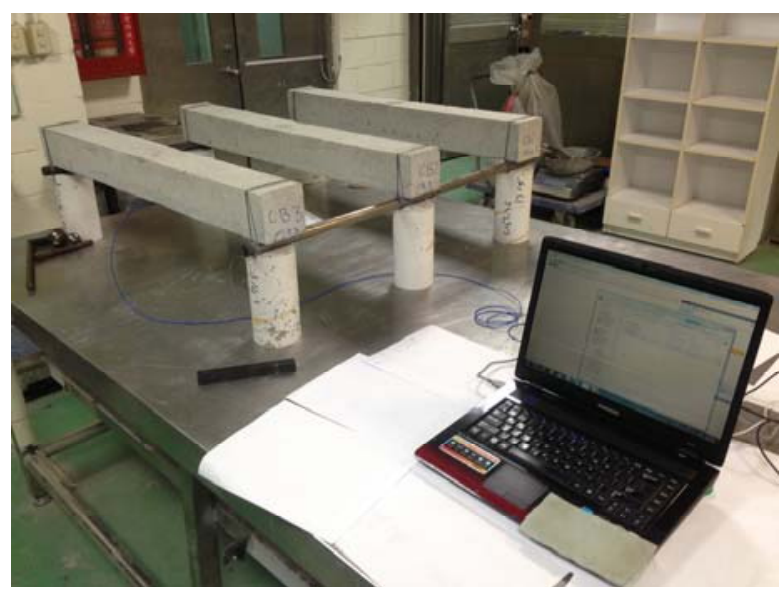

FIGURE III. EXPERIMENTAL SETUP

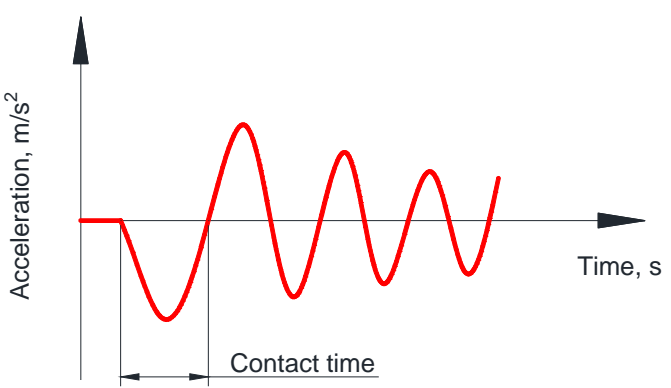

FIGURE IV. SCHEME OF THE CONTACT TIME MEASUREMENT

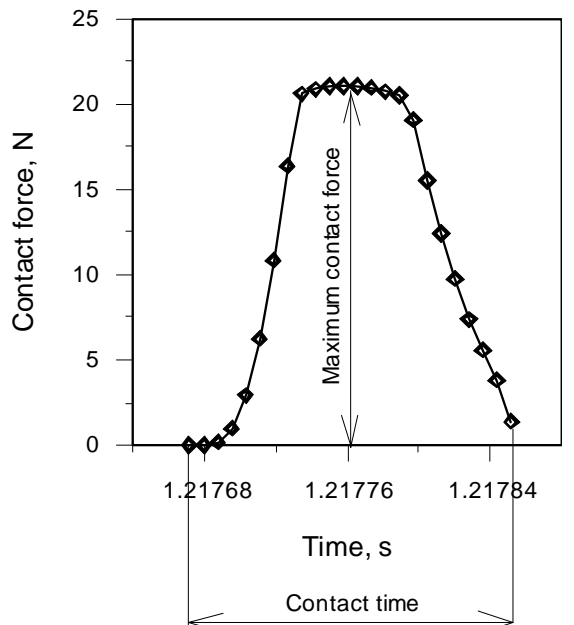

FIGURE V. CONTACT TIME AND CONTACT FORCE MEASUREMENT

\section{RESULTS AND DISCUSSIONS}

As it was mentioned above, the impact tests have been done at the ages of 7, 14, 28, 56, 91 and 182 days. When testing the beams at very early ages, it is important to ensure that they will not break down due to the lack of strength. Compressive strength is a good criterion for such an estimation. At the age of 7 days it was $29.78 \mathrm{MPa}$ and has reached the value of 43.57 MPa at 28 days.

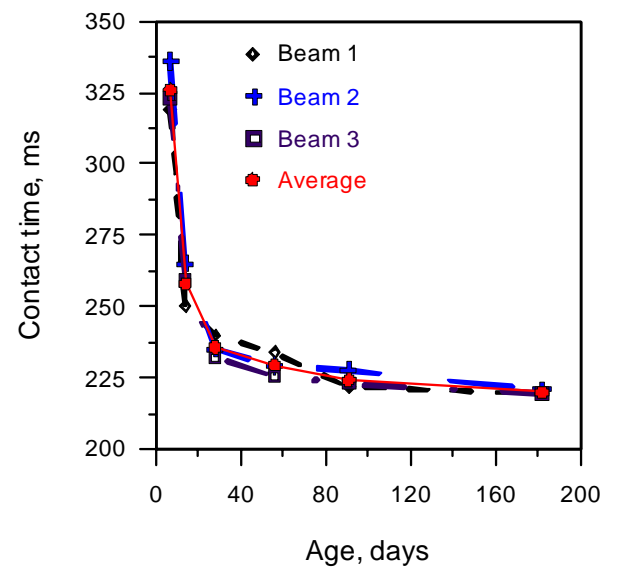

FIGURE VI. DEPENDENCE OF CONTACT TIME ON THE AGE 


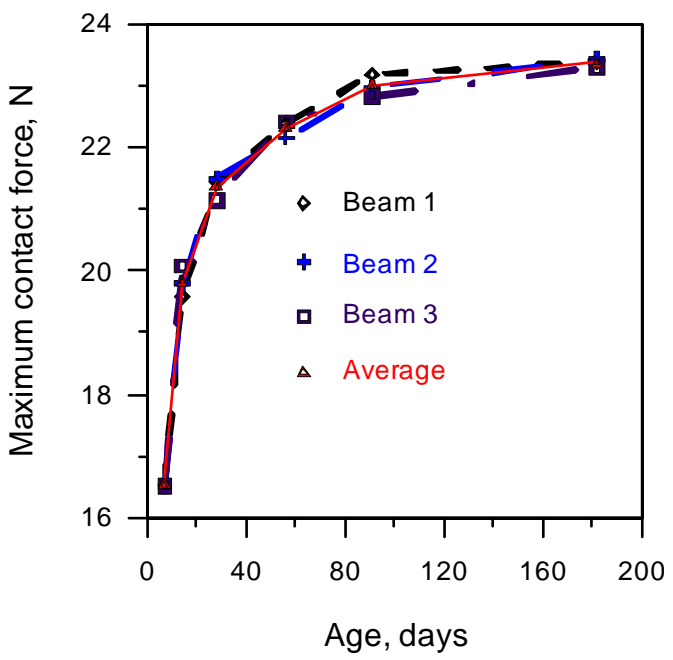

FIGURE VII. DEPENDENCE OF MAXIMUM CONTACT FORCE ON THE CONCRETE AGE

The concrete age dependence of the contact time and maximum contact force are shown on Figures VI and VII, respectively. It could be seen from these two figures that the contact time decreases while the contact force increases with the concrete age. The most significant changes occur at early ages, before 28 days, after that the changes become less significant. Comparing percentage values of the contact time and contact force changes between 7 and 28 days, it could be noted that the average contact time decreased by $27.72 \%$, whereas the average maximum contact force increased by $29.27 \%$. This is related to concrete hardening. When concrete is fresh, it possesses a certain viscosity, which reduces during setting and hardening. At this stage impact time is the longest and the contact force is the smallest due to the damping effect and energy dissipation during the impact. However, after the concrete has gained some strength, damping is reduced, and its effect on the contact force and contact time becomes less significant.

\section{CONCLUSIONS}

The effect of concrete aging on the contact force and contact time during the impact of an steel sphere upon a concrete beam was considered. It was found that the contact force increases with concrete age, while the contact time is decreases. The most significant changes occur at the age before 28 days, after this the process slows down. An average contact time at the age of 28 days is decreased by $27.72 \%$ comparing to its value at 7 days. Average maximum contact force at 28 days increases by $29.27 \%$, respectively. This phenomenon could be explained by the reduction of damping effect and impact energy dissipation with the concrete aging due to its hardening.

\section{ACKNOWLEDGEMENT}

This research was financially supported by the by the international project from the Russian Foundation for Basic Research No.14-08-92008-HHC-a and Taiwan National Science Council No. NSC 103-2923-E-011-002-MY3.

\section{REFERENCES}

[1] Yu.A. Rossikhin, M.V. Shitikova, Two approaches for studying the impact response of viscoelastic engineering systems: An overview, Computers and Mathematics with Applications. 66 (2013) 755-773.

[2] ACI standard C211.1-91 (Reapproved in 2002), Standard Practice for Selecting Proportions for Normal, Heavyweight, and Mass Concrete, American Concrete Institute, 1991.

[3] E. Pristov, W. Dalton, G. Piscsalko, G. Likins, Comparison of Impact-Echo and Broadband Input to Determine Concrete Thickness, Proceedings of a Joint Conference of the 7th Structural Materials Technology: NDE/NDT for Highway and Bridges and The 6th International Symposium on NDT in Civil Engineering, St. Louis, Missouri, U.S.A. (August 14-18, 2006) 254-261. 